\title{
Antihypertensive therapy among newly treated patients: An analysis of adherence and cost of treatment over years
}

This article was published in the following Dove Press journal:

ClinicoEconomics and Outcomes Research

26 July 2010

Number of times this article has been viewed

\author{
Luca Degli Esposti' \\ Stefania Saragoni ${ }^{1}$ \\ Paolo Batacchi \\ Pierangelo Geppetti ${ }^{3}$ \\ Stefano Budal \\ Ezio Degli Esposti ${ }^{4}$ \\ 'CliCon S.r.l., Health, Economics \\ and Outcomes Research, Ravenna; \\ 2Pharmaceutical Policy Department, \\ Local Health Unit of Florence; \\ ${ }^{3}$ Department of Preclinical and \\ Clinical Pharmacology, University of \\ Florence; ${ }^{4}$ Outcomes Research Unit, \\ Policlinics Umberto I, Rome, Italy
}

Correspondence: Luca Degli Esposti CliCon S.r.I., Via Salara, 36, 48I2I,

Ravenna, Italy

Tel +39054438393

Fax +390544 212699

Email luca.degliesposti@clicon.it
Objective: To perform a time-trend analysis of adherence and cost of antihypertensive treatment over four years.

Methods: A population-based retrospective cohort study was conducted. We included subjects $\geq 18$ years, and newly treated for hypertension with diuretics, beta-blockers, calcium channel blockers, angiotensin-converting enzyme inhibitors, or angiotensin receptor blockers between 01 January 2004 and 31 December 2007. One-year adherence to antihypertensive therapy was calculated and classified as low, low-intermediate, intermediate, high-intermediate, and high. The direct cost of antihypertensive medications was evaluated.

Results: We included data for a total of 105,512 patients. The number of newly treated subjects decreased from 27,334 in 2004 to 23,812 in 2007, as well as antihypertensive drug therapy cost which decreased from $€ 2,654,166$ in 2004 to $€ 2,343,221$ in 2007 . On the other hand, in the same time frame, the percentage of adherent newly treated subjects increased from $22.9 \%$ to $28.0 \%$. Compared with subjects initiated on angiotensin receptor blockers (odds ratio $[\mathrm{OR}]=1$ ), the risk of nonadherence was higher in those initiated on angiotensin-converting enzyme inhibitors $(\mathrm{OR}=1.19)$, combination therapy $(\mathrm{OR}=1.44)$, beta-blockers $(\mathrm{OR}=1.56)$, calcium channel blockers $(\mathrm{OR}=1.67)$, and diuretics $(\mathrm{OR}=4.28)$.

Conclusions: The findings of the present study indicate that suboptimal adherence to antihypertensive medication occurs in a substantial proportion of treated patients, and improvements in treatment adherence were obtained but are still unsatisfactory.

Keywords: antihypertensive therapy, adherence, cost, administrative databases

\section{Introduction}

Hypertension is a major risk factor for cardiovascular disease (CVD). In the majority of Western countries, the cost of hypertension and its complications absorbs a large and growing share of health care resources. ${ }^{1}$ In Italy, the expenditure for antihypertensives reached $€ 991.35$ million in 2003. Subtracting expenditure due to use of the same drugs for diseases other than hypertension (around 15\%), total expenditure for antihypertensive therapy (AHT) may be considered to be approximately $€ 840$ million. ${ }^{2}$ Moreover, at the national level, drugs used for CVD continued to show both the highest National Health System (NHS) expenditure (37.5\%) and the highest consumption $(49.0 \%)$ in $2007 .^{3}$

AHT has been clearly shown to reduce both cardiovascular and cerebrovascular events $^{4-7}$ and, consequently, to reduce overall health care costs because of better disease control and lower rates of adverse outcomes. ${ }^{8-13}$ The efficacy of pharmacologic treatment in reducing blood pressure has also been well demonstrated in regimem of chronic and adequately dosed drug use.

submit your manuscript $\mid$ www.dovepress.con 
However, evidence-based guidelines have often failed to impact clinical practice. In current practice, observational studies have shown that $30 \%-70 \%$ of patients with treated hypertension does not persist or adhere to treatment. ${ }^{14-19}$ These results and the considerable pressure on health care systems to provide high-quality care have led several public and private organizations to promote initiatives to monitor and improve hypertension control. Meanwhile, progressive reduction of available financial resources has ushered in a series of measures for controlling costs, such as reductions in drug prices, prescriptions charges for private citizens, and direct distribution of drugs.

The aim of this work is to emphasize the role of adherence to AHT as a key performance indicator in hypertension management. In addition to the existing literature, the present study adds a time-trend analysis of adherence during last years and a pharmacological treatment cost analysis.

\section{Patients and methods Data source}

In Italy the provider of health care for all citizens is the NHS, which is organized into local health units (LHU) throughout the country. Each LHU, as an autonomous body of the NHS, organizes and plans the health care system for a specific area so as to provide services in the community close to where people live. The LHUs have an information network that routinely measures the volumes of expenditure generated by the use of health care services and collects them into computerized reimbursement databases. The data we used were retrieved from three different databases of the LHU of Florence, an area located in the center of Italy, which includes approximately 800,000 beneficiaries: a Beneficiaries' Database, containing patient demographic data, a Medications Prescription Database, providing information for each prescription (such as the prescribing physician's number, anatomical-therapeuticchemical code of the drug purchased, number of packs, number of units per pack, dosages, unit cost per pack and prescription date), and a Hospital Discharge Database, that includes all hospitalization data, with discharge diagnosis codes classified according to the International Classification of Diseases, Ninth Revision (ICD-9). The patient code links electronically between all three databases. The LHU database affords a valuable opportunity to assess the use of AHT in a real practice setting. To guarantee patient privacy, each subject was assigned an anonymous alpha-numeric code. The local ethics committee of the LHU of Florence approved this study.

\section{Cohort definition}

This was a retrospective cohort study, which included only new AHT users, 18 years of age or over, for whom all prescription and clinical outcome data over the study period were compiled. Patients were included if they had received at least one dispensed prescription of AHT (diuretics [ATC code $\mathrm{C} 03$, excluding loop diuretics, mainly used for heart failure], beta-blockers [C07], calcium channel blockers [C08], angiotensin-converting enzyme inhibitors $[\mathrm{C} 09 \mathrm{~A} / \mathrm{B}]$, angiotensin receptor blockers [C09C/D]) between 01 January 2004 and 31 December 2007. The date of the first purchased AHT was defined as the enrolment date. Patients were defined as new users if they had not been prescribed any AHT in the 12 months preceding the enrolment date.

In line with previously published studies,${ }^{20}$ and in order to include only patients treated for hypertension, we excluded any patient who had been diagnosed with heart failure (code 428.X), ischemic heart disease (code 410-414.X), cerebrovascular disorders (code 430-438.X) or other cardiovascular diseases (code 390-400.X, 406459.X, excluding the aforementioned diagnosis codes) in the 12 months before enrolment. In addition, we excluded patients using nitrates in the 12 months preceding treatment initiation because these agents are also indicated in conditions other than hypertension. Only patients with continuous eligibility for at least 24 months (12 months before and 12 months after the enrolment date) were included.

\section{Adherence to AHT medication}

Adherence to AHT was estimated by calculating the proportion of days (proportion of days covered [PDC]) on which a patient had pills available in the time interval of 12 months after the enrolment date (follow-up). The interval was separated into treatment episodes of continuous AHT use based on the method of Catalan. ${ }^{21} \mathrm{~A}$ treatment episode was measured as the time period between the starting date of the first AHT prescription dispensed until the last day supplied on the final dispensed AHT prescription. The latter included a permissible gap following a final dispensing within the specific episode.

Prescriptions filled near the end of the interval contributed days until that date. Prescriptions containing more than one drug contributed to both the sum of the days' supply of all drugs from the same AHT class (to accommodate any stockpiling) and the lower days' supply drug value of drugs from different AHT classes (identifying them as a combined therapy). 
The PDC corresponded to the total of number of days' supply of medication dispensed within each episode divided by the total length of the interval and multiplied by 100 . Consistent with data in the literature, ${ }^{22,23}$ patients were divided into five different categories according to their PDC level, ie, low ( $\mathrm{PDC} \leq 20 \%)$, low-intermediate $(21 \%-40 \%)$, intermediate $(41 \%-60 \%)$, high-intermediate $(61 \%-80 \%)$, or high $(>80 \%)$. They were further classified according to the AHT drug class prescribed at treatment initiation. Cases of multiple class medications, such as calcium channel blockers and angiotensin receptor blockers, were identified as combined therapy.

\section{Statistical analysis}

A four-year descriptive analysis was conducted to evaluate differences in baseline characteristics, use of AHT, and adherence levels across the cohorts of patients identified by enrolment year from 2004 to 2007.

We summarized data as mean values with standard deviations for continuous variables and as numbers (percentages) of subjects for categoric variables. We used Pearson's chisquare test and one-way analysis of variance (ANOVA) to determine significant differences in baseline characteristics across adherence levels.

A multiple logistic regression model was used to estimate odds ratios (OR) and $95 \%$ confidence intervals (CI) and to identify possible factors significantly associated with the risk of nonadherence during 2004-2007. Patients who met the inclusion criteria in more than one of the four previous cohorts were only included once. The PDC was dichotomized, setting a threshold of PDC $\leq 80 \%$ to identify nonadherent patients. The other covariates in the model were age, gender, presence of some medications (at least two prescriptions) evaluated in the 12 months before the enrolment date, antidiabetic agents (ATC code A10), lipid-lowering drugs $(\mathrm{C} 10)$, cardiac therapy $(\mathrm{C} 01$, nitrates excluded), drugs for obstructive airways disease (R03), platelet inhibitors (B01 AC), and initial therapy drug class, with angiotensin receptor blockers as the reference. The year of treatment initiation was also controlled for to account for possible time trends in medication use. Two-tailed $P$ values less than 0.05 were considered statistically significant. All statistical analyses were conducted using SPSS-Windows version 15.0.

\section{Cost analysis}

Only the direct cost of AHT was taken into account. In fact, although it would be important for the decision-maker to consider other direct costs, eg, hospitalizations, control of pharmaceutical expenditure is often considered as the relevant maneuver from the public health care provider point of view, and hence the authors focused on that aspect. ${ }^{24}$ No information on indirect costs was available. Unit costs were taken from the Medications Prescriptions Database containing Italian NHS purchase prices. Each prescription cost was calculated by multiplying the cost per pack by the total number of packs. Since each prescription is unequivocally linked to the patient through the personal health code, the exact direct cost per patient was also known. Costs were adjusted to 2007 prices in the Euro $(€)$ currency.

\section{Results}

A total of 31,483 new AHT patients were enrolled in 2004, 32,888 in 2005, 29,875 in 2006, and 27,456 in 2007, of whom $26.2 \%, 26.8 \%, 25.4 \%$, and $25.7 \%$, respectively, were excluded because of failure to meet our inclusion criteria. In 2004, 1786 patients were excluded as a result of having been hospitalized for a cardiovascular cause before the enrolment date (5.7\% of enrolled subjects) and a further 2363 patients for having used nitrates or loop diuretics in the year prior to enrolment ( $7.5 \%$ of enrolled subjects). Corresponding respective figures for 2005 were 1848 (5.6\% of enrolled subjects) and 2659 (8.1\%); for 2006, 1568 (5.2\%) and 2322 (7.8\%); and for 2007, 1410 (5.1\%) and 2234 (8.1\%). Therefore, 27,334 (21.4\%), 28,381 (20.9\%), 25,985 (19.5\%), and 23,812 (17.8\%) subjects were included in the study in 2004, 2005, 2006, and 2007, respectively. Mean age, gender distribution, and use of hypoglycemic drugs, lipid-lowering drugs, cardiac agents, drugs for obstructive airways disease, and platelet inhibitors are shown in Table 1.

\section{Adherence to AHT}

From 2004 to 2007, low adherence decreased from $33.0 \%$ to $28.5 \%$, while high adherence increased from $22.9 \%$ to $28.0 \%$ (Table 2). Intermediate-low and intermediate-high adherence slightly decreased and increased, respectively. Intermediate adherence remained stable across the study period (from $10.5 \%$ in 2004 to $10.7 \%$ in 2007). Low and intermediate-low adherence patients were younger $(56.9 \pm 17.1$ and $58.4 \pm 16.8$ years, respectively) compared with other levels of adherence (Table 3). Prevalence of male gender was proportional to levels of adherence. Prevalence of use of hypoglycemic drugs, lipid-lowering drugs, and platelet inhibitors increased from low- to high-adherence patients. Use of cardiac therapy was limited. Prevalence of use of drugs for obstructive airways disease decreased with increasing adherence. 
Table I Baseline characteristics of patients newly treated with antihypertensive therapy

\begin{tabular}{|c|c|c|c|c|c|}
\hline & 2004 & 2005 & 2006 & 2007 & $P$ value \\
\hline Patients, n (\%*) & $27,334(21.4)$ & $28,381(20.9)$ & $25,985(19.5)$ & $23,812(17.8)$ & \\
\hline Age, mean (SD), years^ ${ }^{\wedge}$ & $59.9 \pm 15.7$ & $60.1 \pm 15.8$ & $59.8 \pm 15.7$ & $60.8 \pm 15.2$ & $<0.001$ \\
\hline Males (\%) & 42.1 & 42.5 & 42.8 & 42.6 & 0.425 \\
\hline Hypoglycaemic drugs $(\%)^{\dagger}$ & 4.9 & 5.3 & 5.3 & 5.1 & 0.249 \\
\hline Lipid-lowering drugs (\%) ${ }^{\dagger}$ & 4.6 & 4.8 & 4.5 & 5.1 & 0.027 \\
\hline Cardiac therapy $(\%)^{\dagger}$ & 2.0 & 1.9 & 1.8 & 1.6 & 0.017 \\
\hline Drugs for obstructive airways disease $(\%)^{\dagger}$ & 4.6 & 5.1 & 4.5 & 4.4 & $<0.001$ \\
\hline Platelet inhibitors $(\%)^{\dagger}$ & 6.7 & 7.6 & 6.9 & 7.7 & $<0.001$ \\
\hline
\end{tabular}

Notes: *On treated patients; ^At enrolment date; ${ }^{\dagger}$ One year before enrolment date.

Table 4 shows the initiation AHT. In approximately onethird of subjects, angiotensin-converting enzyme inhibitors were the preferred first-line therapy. In contrast, combination therapy was rarely used as first-line therapy. From 2004 to 2007, the proportion of prescriptions for diuretics decreased (from $24.0 \%$ to $20.8 \%$ ), increased slightly for beta-blockers (from $14.8 \%$ to $16.1 \%$ ), decreased slightly for calcium channel blockers (from $9.5 \%$ to $7.7 \%$ ), whilst use of angiotensinconverting enzyme inhibitors and combinations as starting therapy remained stable ( $35.5 \%$ to $35.3 \%$ and $4.9 \%$ to $5.5 \%$, respectively), and use of angiotensin receptor blockers significantly increased (from $11.4 \%$ to $14.7 \%$ ).

Adherence levels varied significantly among drugs used for treatment initiation (Table 5). In particular, low adherence was highest among subjects started on diuretics $(54.7 \%$ of included subjects) and lowest among those started on angiotensin receptor blockers (13.0\%). Subjects started on a combination therapy showed low adherence in $36.8 \%$ of cases. High adherence was highest among subjects initiated on angiotensin receptor blockers (33.4\%) and lowest among subjects started on diuretics $(10.1 \%)$. Subjects starting with angiotensin-converting enzyme inhibitors displayed high adherence in $29.9 \%$ of cases. Compared with subjects initiated on angiotensin receptor blockers, the risk of nonadherence was 19\% higher in those initiated on angiotensinconverting enzyme inhibitors, $44 \%$ higher in those initiated on combination therapy, $56 \%$ higher in those initiated on beta-blockers, $67 \%$ higher in those initiated on calcium channel blockers, and more than four-fold (4.3 times) higher in those initiated on diuretics (Table 6).

\section{Cost analysis of AHT}

The overall cost of AHT for the one-year follow-up was $€ 2,654,166$ in $2004, € 2,664,815$ in 2005 ( $+0.4 \%$ compared with 2004), €2,339,704 in 2006 (-12.2\% compared with 2005), and $€ 2,343,221$ in 2007 ( $+0.2 \%$ compared with 2006 and $-11.7 \%$ compared with 2004, Table 7). The percentage of overall cost of AHT allocated to high adherence patients ranged from $60.7 \%$ in 2004 , to $59.5 \%$ in $2005,60.6 \%$ in 2006 , and $64.9 \%$ in 2007 . Overall costs allocated to low and intermediate-low adherence patients decreased during the study period. The mean cost of AHT for the one-year follow-up decreased in each level of adherence. In high adherence, the mean cost decreased from €256.97 in 2004 to $€ 228.21$ in 2007 (Table 8).

\section{Discussion}

Many studies have highlighted poor adherence in subjects newly treated with AHT, ${ }^{14-19}$ but few of them have evaluated how adherence levels vary over time.$^{20}$ The present study provides some additional information about AHT among newly treated patients. First, it measures the number of subjects initiating pharmacologic treatment and gives information

Table 2 Time trends for adherence level by enrolment year

\begin{tabular}{lllllll}
\hline Year of treatment & \multicolumn{6}{l}{ Proportion of patients according to adherence level, $\mathbf{n}(\%) *$} \\
\cline { 2 - 7 } initiation & Low & Intermediate-low & Intermediate & Intermediate-high & High & Total \\
\hline 2004 & $9009(33.0)$ & $6068(22.2)$ & $2878(10.5)$ & $3106(11.4)$ & $6273(22.9)$ & $27,334(100.0)$ \\
2005 & $9358(33.0)$ & $6624(23.3)$ & $317 \mid(I I .2)$ & $3053(10.8)$ & $6175(21.8)$ & $28,381(100.0)$ \\
2006 & $858 I(33.0)$ & $5959(22.9)$ & $2682(10.3)$ & $2861(11.0)$ & $5902(22.7)$ & $25,985(100.0)$ \\
2007 & $6790(28.5)$ & $485 I(20.4)$ & $2554(10.7)$ & $2956(12.4)$ & $6661(28.0)$ & $23,812(100.0)$ \\
\hline
\end{tabular}

Notes: *Adherence was defined as: low (PDC $\leq 20 \%$ ); intermediate-low (PDC, $21 \%-40 \%$ ); intermediate (PDC, 41\%-60\%); intermediate-high (PDC, 61\%-80\%); high (PDC $>80 \%$ ); overall $\chi^{2}$ test, $P<0.001$.

Abbreviation: PDC, proportion of days covered. 
Table 3 Baseline characteristics of patients by level of adherence to treatment, 2004-2007

\begin{tabular}{|c|c|c|c|c|c|c|}
\hline & \multicolumn{6}{|c|}{ Adherence levels* } \\
\hline & Low & Intermediate-low & Intermediate & Intermediate-high & High & $P$ value \\
\hline Patients, n (\%) & $30,915(32.6)$ & $20,933(22.0)$ & $9,785(10.3)$ & $10,6 \mid 4(11.2)$ & $22,700(23.9)$ & \\
\hline Age, mean (SD), years ${ }^{\wedge}$ & $56.9 \pm 17.1$ & $58.4 \pm 16.8$ & $61.9 \pm 15.0$ & $62.8 \pm 13.6$ & $62.6 \pm 12.7$ & $<0.001$ \\
\hline Male (\%) & 38.2 & 41.9 & 41.4 & 44.7 & 50.2 & $<0.001$ \\
\hline Hypoglycaemic drugs $(\%)^{\dagger}$ & 3.5 & 4.5 & 5.2 & 6.0 & 7.2 & $<0.001$ \\
\hline Lipid lowering drugs (\%) ${ }^{\dagger}$ & 3.7 & 4.2 & 5.2 & 5.5 & 5.8 & $<0.001$ \\
\hline Cardiac therapy $(\%)^{\dagger}$ & 1.5 & 1.8 & 1.8 & 1.9 & 2.0 & $<0.001$ \\
\hline $\begin{array}{l}\text { Drugs for obstructive airways } \\
\text { disease }(\%)^{\dagger}\end{array}$ & 5.2 & 5.0 & 4.1 & 3.8 & 3.9 & $<0.001$ \\
\hline Platelet inhibitors (\%) & 5.5 & 6.4 & 8.0 & 8.2 & 8.6 & $<0.001$ \\
\hline
\end{tabular}

Notes: *Adherence was defined as: low (PDC $\leq 20 \%$ ); intermediate-low (PDC, 21\%-40\%); intermediate (PDC, 4l\%-60\%); intermediate-high (PDC, 61\%-80\%); high (PDC > 80\%). ^At the enrolment date; ${ }^{\dagger}$ One year before enrolment date.

Abbreviation: PDC, proportion of days covered.

on patient characteristics and cost of AHT over time. From 2004 to 2007 , there was a $12.9 \%$ decrease in the number of patients initiated on AHT (from $21.4 \%$ to $17.8 \%$ ) as well as an $11.7 \%$ decrease in the overall cost of AHT for the oneyear follow-up (from $€ 2,654,166$ in 2004 to $€ 2,343,221$ in 2007). This findings may be the result of reductions both in the number of patients started on AHT and in drug prices, rather than attributable to a shift in prescribing preferences for cheaper therapeutic options (see Table 4). These preliminary findings seem to show a trend towards economic savings in pharmaceutical expenditure by reducing the number of patients starting AHT. In particular, the reduction of initiated patients refers to low adherence (from 9009 to 6790 patients) and to low-intermediate adherence (from 6068 to 4851 patients) but does not refer to higher levels of adherence (Table 2). Because low and low-intermediate adherence patients indicate a lower risk compared with those with higher adherence (Table 3), these findings seem to underline a therapeutic approach strategy which pays more attention to patient characteristics before initiating pharmacologic treatment. Understanding how patient adherence to pharmacologic treatment varies on the basis of demographic and clinical characteristics, decision-makers could better focus on those categories of patients who are more likely not to adhere to treatment, ie, younger men and those taking no concomitant cardiovascular medications (Tables 3 and 4). This strategy could be particularly effective, especially if the resources saved could be reallocated to priority patients, ie, those at higher risk of CVD and those who need improvement in their adherence.

Second, a high amount of AHT expenditure was accounted for by nonadherent patients, although this decreased over time (from $39.3 \%$ of the overall cost in 2004 to $35.1 \%$ in 2007). Resources allocated to regimes not adhered to can be considered inappropriate both in the short term (because blood pressure is not effectively controlled) and in the long term (because the opportunity to decrease the costs of cardiovascular complications is missed).

Third, the present four-year analysis of adherence shows a low rate of increase in adherence (from $22.9 \%$ in 2004 to $28.0 \%$ of newly treated subjects in 2007) suggesting the need for more effective interventions. Recently, the EUROASPIRE III (European Action on Secondary and Primary Prevention by Intervention to Reduce Events III) survey showed that blood pressure control did not improve with time, and indeed showed a $10 \%$ worsening over the three survey periods. ${ }^{25}$

Table 4 Antihypertensive drug classes used at treatment initiation

\begin{tabular}{|c|c|c|c|c|c|}
\hline & 2004 & 2005 & 2006 & 2007 & Total \\
\hline Diuretics, n (\%) & $6553(24.0)$ & $6254(22.0)$ & $5686(21.9)$ & $4955(20.8)$ & $23,448(22.2)$ \\
\hline Beta-blockers, n (\%) & 4059 (14.8) & $4129(14.5)$ & $3877(14.9)$ & $3826(16.1)$ & $|5,89|(15.1)$ \\
\hline Calcium channel blockers, n (\%) & $2594(9.5)$ & $264 I(9.3)$ & $2316(8.9)$ & $1822(7.7)$ & $9373(8.9)$ \\
\hline $\begin{array}{l}\text { Angiotensin-converting enzyme } \\
\text { inhibitors, } n(\%)\end{array}$ & $9691(35.5)$ & $9706(34.2)$ & $8857(34.1)$ & $8414(35.3)$ & $36,668(34.8)$ \\
\hline Angiotensin receptor & $3103(11.4)$ & $387 \mid(\mid 3.6)$ & $3585(13.8)$ & $3496(14.7)$ & $14,055(13.3)$ \\
\hline blockers, n (\%) & & & & & \\
\hline Combined therapy, $\mathrm{n}(\%)$ & I $334(4.9)$ & $1780(6.3)$ & $1664(6.4)$ & $1299(5.5)$ & $6077(5.8)$ \\
\hline
\end{tabular}

Note: Overall $\chi^{2}$ test, $P<0.001$. 
Table 5 Antihypertensive drug classes used at treatment initiation according to adherence level, 2004-2007

\begin{tabular}{|c|c|c|c|c|c|}
\hline & \multicolumn{5}{|c|}{ Adherence levels* } \\
\hline & Low & Intermediate-low & Intermediate & Intermediate-high & High \\
\hline Diuretics, n (\%) & II,533 (54.7) & $42 \mid 4(20.0)$ & $1709(8.1)$ & $1479(7.0)$ & $2133(10.1)$ \\
\hline Beta-blockers, n (\%) & $3081(21.9)$ & $3969(28.2)$ & $2017(14.3)$ & $1886(13.4)$ & $3120(22.2)$ \\
\hline $\begin{array}{l}\text { Calcium channel } \\
\text { blockers, n (\%) }\end{array}$ & $2494(29.2)$ & $2315(27.1)$ & 980 (II.5) & $820(9.6)$ & $1932(22.6)$ \\
\hline $\begin{array}{l}\text { Angiotensin-converting } \\
\text { enzyme inhibitors, } n(\%)\end{array}$ & $10,137(30.5)$ & $5508(16.6)$ & $3246(9.8)$ & $4370(13.2)$ & $9922(29.9)$ \\
\hline $\begin{array}{l}\text { Angiotensin receptor } \\
\text { blockers, n (\%) }\end{array}$ & $1637(13.0)$ & $3825(30.4)$ & I357 (I0.8) & I544 (I2.3) & $4202(33.4)$ \\
\hline Combined therapy, $\mathrm{n}(\%)$ & $2033(36.8)$ & $1102(20.0)$ & $476(8.6)$ & $515(9.3)$ & |39| (25.2) \\
\hline
\end{tabular}

Notes: *Adherence was defined as: low (PDC $\leq 20 \%$ ); intermediate-low (PDC, $21 \%-40 \%$ ); intermediate (PDC, $41 \%-60 \%)$; intermediate-high (PDC, 61\%-80\%); high (PDC $>80 \%$ ). Overall $\chi^{2}$ test, $P<0.001$.

Abbreviation: PDC, proportion of days covered.

The low increase in rates of adherence would indicate no increase in the proportion of patients achieving blood pressure control in clinical practice. As shown in recent studies, failures in reaching high adherence with AHT implies avoidable CVD hospitalizations and deaths ${ }^{8-13}$ and increasing costs for the management of hypertension and related diseases. ${ }^{1,11,26}$ In 2003, the World Health Organization alerted health authorities and clinicians about poor adherence to chronic pharmacologic treatments in clinical practice and suggested the need for action. ${ }^{27}$ According to existing evidence, more

Table 6 Multivariate analysis of the association of initial antihypertensive drug class with nonadherence to treatment

\begin{tabular}{|c|c|c|}
\hline & OR $(95 \% \mathrm{Cl})$ & $P$ value \\
\hline Age, years^ ${ }^{\wedge}$ & $0.98(0.98-0.98)$ & $<0.001$ \\
\hline \multicolumn{3}{|l|}{ Gender } \\
\hline Male & 1.00 & \\
\hline Female & $0.74(0.72-0.77)$ & $<0.001$ \\
\hline \multicolumn{3}{|l|}{ Year of start } \\
\hline 2004-2005 & 1.00 & \\
\hline 2006-2007 & $0.86(0.80-0.92)$ & $<0.001$ \\
\hline \multicolumn{3}{|l|}{$\begin{array}{l}\text { Medications before the enrolment } \\
\text { date*t }\end{array}$} \\
\hline Hypoglycaemic drugs & $0.78(0.73-0.83)$ & $<0.001$ \\
\hline Lipid-lowering drugs & $0.86(0.80-0.92)$ & $<0.001$ \\
\hline Cardiac therapy & $0.98(0.87-I .10)$ & 0.663 \\
\hline Drugs for obstructive airways disease & $1.24(1.15-1.35)$ & $<0.001$ \\
\hline Platelet inhibitors & $0.98(0.93-1.04)$ & 0.579 \\
\hline \multicolumn{3}{|l|}{ Enrolment drug class } \\
\hline Angiotensin receptor blockers & 1.00 & \\
\hline $\begin{array}{l}\text { Angiotensin-converting enzyme } \\
\text { inhibitors }\end{array}$ & $1.19(1.14-1.24)$ & $<0.001$ \\
\hline Combined therapy & I.44 (I.34-I.55) & $<0.001$ \\
\hline Beta-blockers & $1.56(1.47-1.65)$ & $<0.001$ \\
\hline Calcium channel blockers & I.67 (I.57-I.78) & $<0.001$ \\
\hline Diuretics & $4.28(4.04-4.54)$ & $<0.001$ \\
\hline
\end{tabular}

A total of 94,947 patients were considered in the model.

Notes: ^At enrolment date; *Absence of medication as reference; ${ }^{\dagger}$ One year before enrolment date. effective interventions should be planned and developed. Discordance also between the ideal scenario and the results obtained from our study should increase awareness among health care providers of the need for better performance. From the perspective of enhancing treatment adherence, use of angiotensin receptor blockers as first-line therapy should be considered because these agents have shown the highest rates of high adherence and, above all, the lowest rate of early discontinuation (Table 5). Our findings with regard to poor adherence should be considered both by clinicians when selecting first-line therapy and by health care providers when defining their pharmaceutical formularies.

\section{Limitations}

The principal limitation of this study is its lack of inclusion of patient clinical data. The study was conducted by crosslinking administrative databases. These $a d$ hoc databases are comparable with the health care claims databases which have been utilized for outcomes research for years in the US and Canada. ${ }^{28,29}$ Because these databases are normally used for administrative or accounting purposes, they omit information that would make it possible to determine the clinical status of patients. The absence of clinical outcomes data, in particular blood pressure control, could have generated bias, leading to comparisons of patients with different levels of disease severity. In addition, the data source does not provide any information about the diagnosis of hypertension, thus the possibility of disease misclassification cannot be excluded. Moreover, information about patient lifestyle habits and health status information, ie, physical activity levels, smoking status, and other determinants of CVD morbidity and mortality, were not available. The potential confounding effect of this lack of information on the association between adherence to antihypertensives and CVD events should be investigated. 
Table 7 Time trends of total annual cost of antihypertensive treatment according to adherence levels

\begin{tabular}{|c|c|c|c|c|c|c|c|c|}
\hline \multirow[t]{2}{*}{ Adherence level ${ }^{\dagger}$} & \multicolumn{2}{|l|}{2004} & \multicolumn{2}{|l|}{2005} & \multicolumn{2}{|l|}{2006} & \multicolumn{2}{|l|}{2007} \\
\hline & Total cost $(€)$ & $\%$ & Total cost $(€)$ & $\%$ & Total cost $(€)$ & $\%$ & Total cost $(€)$ & $\%$ \\
\hline Low & $|30,80| .97$ & 4.9 & $133,476.75$ & 5.0 & $117,422.46$ & 5.0 & $79,164.58$ & 3.4 \\
\hline Intermediate-low & $235,841.75$ & 8.9 & $259,473.22$ & 9.7 & $216,699.54$ & 9.3 & $166,970.06$ & 7.1 \\
\hline Intermediate & $233,171.04$ & 8.8 & $255,847.65$ & 9.6 & $206,623.53$ & 8.8 & $195,960.19$ & 8.4 \\
\hline Intermediate-high & $442,365.89$ & 16.7 & $43 I, 45 I .72$ & 16.2 & $379,979.08$ & 16.2 & $381,023.85$ & 16.3 \\
\hline High & I,6II,985.3। & 60.7 & $\mathrm{I}, 584,565.78$ & 59.5 & I,418,978.99 & 60.6 & $\mathrm{I}, 520,102.4 \mathrm{I}$ & 64.9 \\
\hline Total & $2,654,165.96$ & 100.0 & $2,664,815.12$ & 100.0 & $2,339,703.60$ & 100.0 & $2,343,221.09$ & 100.0 \\
\hline
\end{tabular}

Notes: ${ }^{\dagger}$ Adherence was defined as: low (PDC $\leq 20 \%$ ); intermediate-low (PDC, 21\%-40\%); intermediate (PDC, $41 \%-60 \%$ ); intermediate-high (PDC, 61\%-80\%); high (PDC > 80\%). Abbreviation: PDC, proportion of days covered.

Another important limitation related to the source of the data is the lack of information on the indication for AHT. To increase the likelihood that AHT was used for hypertension, patients with known CVD were excluded from the study. Moreover, the available data included only drugs dispensed, rather than drugs consumed. Therefore, we may have overestimated adherence. However, the data suggest a good correlation between pharmacy dispensing records and cumulative drug exposure. ${ }^{22}$ Finally, only direct costs were included, but indirect and intangible costs have no actual financial implications for health care structure and should be considered only for a societal perspective. ${ }^{1}$

\section{Conclusions}

The findings of the present study show that adherence to AHT improved slowly from $22.9 \%$ to $28.0 \%$ in newly treated subjects over four years. Local services should therefore be alerted to the need for routine monitoring of adherence to AHT, because this is a key performance indicator for both management of hypertensive patients and overall cost minimization in CVD. Administrative databases, even if lacking patient lifestyle and health status information, offer a lowcost monitoring option, and include sufficiently accurate data for representative populations.

Table 8 Time trends of mean annual cost of antihypertensive treatment according to adherence levels

\begin{tabular}{lllll}
\hline Adherence level $^{\dagger}$ & $\mathbf{2 0 0 4}$ & $\mathbf{2 0 0 5}$ & $\mathbf{2 0 0 6}$ & $\mathbf{2 0 0 7}$ \\
\hline Low & 14.52 & 14.26 & 13.68 & 11.66 \\
Intermediate-low & 38.87 & 39.17 & 36.37 & 34.42 \\
Intermediate & 81.02 & 80.68 & 77.04 & 76.73 \\
Intermediate-high & 142.42 & 141.32 & 132.81 & 128.90 \\
High & 256.97 & 256.61 & 240.42 & 228.21 \\
Total & 97.10 & 93.89 & 90.04 & 98.41 \\
\hline
\end{tabular}

Notes: ${ }^{\dagger}$ Adherence was defined as: low (PDC $\leq 20 \%$ ); intermediate-low (PDC, $21 \%-40 \%$ ); intermediate (PDC, $41 \%-60 \%$ ); intermediate-high (PDC, 61\%-80\%); high (PDC > 80\%).

Abbreviation: PDC, proportion of days covered.

\section{Acknowledgments}

The cooperation of Dr Alessandra Fionda in this research is gratefully acknowledged.

\section{Disclosure}

This study was funded by Takeda Italia Farmaceutici. Otherwise there is no conflict of interest in this work and there were no persons who contributed to the work who did not meet the criteria for authorship.

\section{References}

1. Degli Esposti L, Valpiani G. Pharmacoeconomic burden of undertreating hypertension. Pharmacoeconomics. 2004;22(14):907-928.

2. Robbiano L, Martelli A, Brambilla G. Discrepancies between use of antihypertensive drugs and guidelines indications: Pharmacoeconomic implications. J Hum Hypertens. 2005;19(10):819-822.

3. The use of pharmaceuticals in Italy. National Report 2007. Rome: Il Pensiero Scientifico Editore; 2008.

4. Psaty BM, Lumley T, Furberg CD, et al. Health outcomes associated with various antihypertensive therapies used as first-line agents: A network meta analysis. JAMA. 2003;289(19):2534-2544.

5. Turnbull F; Blood Pressure Lowering Treatment Trialists' Collaboration. Effects of different blood pressure lowering regimens on major cardiovascular events: Second cycle of prospectively designed overviews. Lancet. 2003(9395);362:1527-1535.

6. Chalmers J. Comparison of various blood pressure lowering treatments on the primary prevention of cardiovascular outcomes in recent randomised clinical trials. Clin Exp Hypertens. 2004;26(7-8):709-719.

7. Turnbull F, Neal B, Ninomiya T, et al. Effects of different regimens to lower blood pressure on major cardiovascular events in older and younger adults: Meta-analysis of randomised trials. Blood Pressure Lowering Treatment Trialists' Collaboration. BMJ. 2008;336 (7653):1121-1223.

8. Rasmussen JN, Chong A, Alter DA. Relationship between adherence to evidence-based pharmacotherapy and long-term mortality after acute myocardial infarction. JAMA. 2007;297(2):177-186.

9. Ho PM, Rumsfeld JS, Masoudi FA, et al. Effect of medication nonadherence on hospitalization and mortality among patients with diabetes mellitus. Arch Intern Med. 2006;166(17):1836-1841.

10. Ho PM, Spertus JA, Masoudi FA, et al. Impact of medication therapy discontinuation on mortality after myocardial infarction. Arch Intern Med. 2006;166(17):1842-1847.

11. Sokol MC, McGuigan KA, Verbrugge RR, et al. Impact of medication adherence on hospitalization risk and healthcare cost. Med Care. 2005;43(6):521-530.

12. Kettani FZ, Dragomir A, Coté R, et al. Impact of a better adherence to antihypertensive agents on cerebrovascular disease for primary prevention. Stroke. 2009;40(1):213-220. 
13. Mazzaglia G, Ambrosioni E, Alacqua M, et al. Adherence to antihypertensive medications and cardiovascular morbidity among newly diagnosed hypertensive patients. Circulation. 2009;120(16):1598-1605.

14. Degli Esposti L, Degli Esposti E, Valpiani G, et al. A retrospective, population-based analysis of persistence with antihypertensive drug therapy in primary care practice in Italy. Clin Ther. 2002;24(8):1347-1357.

15. Degli Esposti L, Di Martino M, Saragoni S, et al. Pharmacoeconomics of antihypertensive drug treatment: An analysis of how long patients remain on various antihypertensive therapies. J Clin Hypertens. 2004;6(2):76-84.

16. Degli Esposti E, Sturani A, Di Martino M, et al. Long-term persistence with antihypertensive drugs in new patients. $J$ Hum Hypertens. 2002;16(6):439-444.

17. Caro JJ, Salas M, Speakman JL, et al. Persistence with treatment for hypertension in actual practice. Can Med Assoc J. 1999:160(1):3-7.

18. Mazzaglia G, Mantovani L, Sturkenboom MC, et al. Patterns of persistence with antihypertensive medications in newly diagnosed hypertensive patients in Italy: A retrospective cohort study in primary care. J Hypertens. 2005;23(11):2093-2100.

19. Corrao G, Zambon A, Parodi A, et al. Discontinuation of and changes in drug therapy for hypertension among newly-treated patients: A population-based study in Italy. J Hypertens. 2008;26(4):819-24.

20. Breekveldt-Postma N, Penning-van Beest F, Siiskonen S, et al. The effect of discontinuation of antihypertensives on the risk of acute myocardial infarction and stroke. Curr Med Res Opin. 2008;24(1): 121-127.
21. Catalan VS, LeLorier J. Predictors of long-term persistence on statins in a subsidized clinical population. Value Health. 2000;3(6):417-426.

22. Perreault S, Dragomir A, White M, Lalonde L, Blais L, Bérard A. Better adherence to antihypertensive agents and risk reduction of chronic heart failure. J Intern Med. 2009;266(2):207-218.

23. Degli Esposti L, Di Martino M, Saragoni S, Capone A, Russo P, Degli Esposti E. Cost offset of lipid-lowering drugs for primary and secondary prevention of cardiovascular disease. Expert Rev Pharmacoecon Outcomes Res. 2005;5(2):193-205.

24. Baio G, Esposti LD, Esposti ED, et al. Bayesian cost-effectiveness analysis based on the persistence with antihypertensive treatment. Expert Rev Pharmacoecon Outcomes Res. 2003;3(3):227-236.

25. Kotseva K, Wood D, De Backer D, et al; for the EUROASPIRE Study Group. Cardiovascular prevention guidelines in daily practice: Comparison of EUROASPIRE I, II, and III surveys in eight European countries. Lancet. 2009;373(9667):929-940.

26. Gaziano TA, Bitton A, Anand S, et al. The global cost of non optimal blood pressure. J Hypertens. 2009;27:1472-7.

27. World Health Organization. Adherence to long-term therapies. Evidence for action. Geneva: World Health Organization; 2003.

28. Motheral BR, Fairman KA. The use of claims databases for antihypertensive drugs and associated hospitalization. Clin Ther. 1997; 19(2):346-366

29. Birnbaum HG, Cremieux PY, Greenberg PE, et al. Using health care expenditures for healthcare claims data for outcome research and pharmaco-economic analyses. Pharmacoeconomics. 1999;16:1-8.
ClinicoEconomics and Outcomes Research

\section{Publish your work in this journal}

ClinicoEconomics \& Outcomes Research is an international, peerreviewed open-access journal focusing on Health Technology Assessment, Pharmacoeconomics and Outcomes Research in the areas of diagnosis, medical devices, and clinical, surgical and pharmacological intervention. The economic impact of health policy and health systems

\section{Dovepress}

organization also constitute important areas of coverage. The manuscript management system is completely online and includes a very quick and fair peer-review system, which is all easy to use. Visit http://www.dovepress.com/testimonials.php to read real quotes from published authors. 